Letter to the Editor

\title{
How many young drivers do not meet the driver licencing vision requirements?
}

\author{
Margaret Y. Tu MD, ${ }^{1}$ Seyhan Yazar PhD, ${ }^{1,2}$ David A. Mackey MD FRANZCO ${ }^{1,3,4}$ and \\ Samantha S. Lee $\mathrm{PhD}^{1}$
}

${ }^{1}$ Centre for Ophthalmology and Visual Sciences (incorporating Lions Eye Institute), University of Western Australia, Perth, WA, Australia

2Single Cell and Computational Genomics Lab, Garvan Institute of Medical Research, Sydney, NSW, Australia

${ }^{3}$ Centre for Eye Research Australia, University of Melbourne, Royal Victorian Eye and Ear Hospital, East Melbourne, VIC, Australia

${ }^{4}$ School of Medicine, Menzies Research Institute Tasmania, University of Tasmania, Hobart, TAS, Australia

Correspondence: Dr Samantha SY Lee, Centre for Ophthalmology and Visual Sciences, University of Western Australia and the Lions Eye Institute, 2 Verdun St, Nedlands, WA 6009, Australia

Email: samantha.sy.lee29@gmail.com

Received 12 April 2020; accepted 24 April 2020

Funding sources / Financial disclosure: The Gen2 20-year follow-up of the Raine study was funded by the Australian National Health and Medical Research Council (NHMRC) project grant 1021105, the Australian Foundation for the Prevention of

This is the author manuscript accepted for publication and has undergone full peer review but has not been through the copyediting, typesetting, pagination and proofreading process, which may lead to differences between this version and the Version of Record. Please cite this article as doi: $10.1111 /$ ceo.13772

This article is protected by copyright. All rights reserved. 
Blindness, the Ophthalmic Research Institute of Australia, and the BrightFocus Foundation. SY is supported by a NHMRC Early Career Fellowship. The core management of the Raine Study is funded by the University of Western Australia (UWA), the Telethon Institute for Child Health Research, the Raine Medical Research Foundation, the UWA Faculty of Medicine, Dentistry and Health Sciences, the Women's and Infant's Research Foundation, Curtin University, Murdoch University, Edith Cowan University, and the University of Notre Dame Australia.

Conflict of interest: None 
Driving is a highly visual task; poorer vision has been linked to reduced driving safety. ${ }^{1}$ In a population-based study, Keeffe et al. ${ }^{2}$ reported that uncorrected refractive error is the major cause of impaired vision in middle-aged and older drivers. As the prevalence of myopia increases worldwide and in Australia, ${ }^{3}$ especially in the younger demographic, we may expect a significant proportion of young adults failing to meet the vision standard for a private driver licence in Australia (i.e. VA of 6/12 in the better seeing eye) or have sub-optimal vision due to under-/uncorrected myopia. Here, we assessed the visual acuity (VA) and refractive error of young licenced drivers in Western Australia.

This was conducted as part of the Raine Study, a longitudinal study that has followed a cohort since their birth in 1989-1992. At the 20-year follow-up of the Raine Study ${ }^{4}$ conducted in 2010-2012, 1,344 participants completed an eye examination. The nature of the study was fully explained to participants and written informed consent was obtained. This study complied with the tenets of the Declaration of Helsinki and was approved by the University of Western Australia's Human Research Ethics Committee.

Presenting VA (habitual driving correction), post-cycloplegic autorefraction, and spectacle lens were measured. Amount of under-correction was determined using the dioptric difference in spherical equivalent between the autorefraction and spectacle lens measurements (if any).

Of the 1,344 participants, 428 did not provide information on whether they had a driver's licence and 196 did not have a driver's licence at the time of their eye assessment, leaving a total of 720 licenced drivers included in the analysis (19-22 years old, $48.3 \%$ males).

Five participants ( $0.7 \%$ of sample; 1 male) had presenting better eye VA of worse than $6 / 12$. Two of these 5 participants did not wear spectacles and had uncorrected myopia by at least -1.50D; 2 participants wore spectacles but were under-corrected for their myopia by -1.00 to $-1.75 \mathrm{D}$; and 1 had uncorrected astigmatism of $-0.75 \mathrm{DC}$ 
in each eye. For all of these participants, VAs improved to $6 / 7.5$ or better with pinholes.

There were in total 123 (14.5\%; 62 males) participants with under-/uncorrected myopia by at least $-0.5 \mathrm{D}$, including 42 (4.9\%; 18 males) and 6 ( $0.7 \% ; 2$ male) who were under-/uncorrected by at least -1D and -2D, respectively. There was no difference by sex between those with and without under-/uncorrected myopia or VA less than $6 / 12$ ( $p>0.05)$.

These findings have important implications for road safety as low levels of refractive blur have been shown to impair driving performance, even if an individual's VA still meets the driving vision standard. ${ }^{5} \mathrm{~A}$ closed-road driving study ${ }^{5}$ reported that inducing refractive blur at low levels (using +0.5D, +1D, +2D optical lenses) resulted in the driver recognising fewer road signs and having shorter distance-tosign recognition as well as poorer detection and avoidance of hazards compared to best-corrected VA, with these effects exacerbated during night-time. The authors of that study have also previously demonstrated that refractive blur has a larger impact on the driving performance of young adults compared to their older counterparts. Furthermore, at 19-22 years old, many of the drivers we studied may be novices, who are known to have higher crash rates. In those drivers whose presenting VA was the VA could be improved with pinhole, which shows that they simply needed an updated prescription. As refractive error may progress in early adulthood after a person initially receives a driver's licence, we recommend that younger drivers have regular eye examinations on a yearly basis or as recommended by their eyecare practitioner to detect changes in refractive error.

\section{Acknowledgements}

We would like to acknowledge the Raine Study participants and their families for their continued support for the Raine Study, as well as the Raine Study staff and Lions Eye Institute staff and students for assisting in the cohort coordination and data collection. We additionally thank Prof Peter Eastwood, A/Prof Nigel McArdle, 
and Prof Leon Straker for initiating the driving status questionnaire in the study, and Dr Hannah Forward for her assistance with the study. 


\section{REFERENCES}

1 Owsley, C. \& McGwin, G., J r. Vision and driving. Vision Res. 50, 2348-2361 (2010).

2 Keeffe, J. E., J in, C. F., Weih, L. M., McCarty, C. A. \& Taylor, H. R. Vision impairment and older drivers: who's driving? $\mathrm{Br}$ J Ophthalmo/ 86, 1118-1121 (2002).

3 Holden, B. A. et al. Global Prevalence of Myopia and High Myopia and Temporal Trends from 2000 through 2050. Ophthalmology 123, 1036-1042, doi:10.1016/j.ophtha.2016.01.006 (2016).

4 Yazar, S. et al. Raine eye health study: design, methodology and baseline prevalence of ophthalmic disease in a birth-cohort study of young adults. Ophthalmic Genet. 34, 199-208, doi:10.3109/13816810.2012.755632 (2013).

5 Wood, J. M. et al. Differential effects of refractive blur on day and nighttime driving performance. Invest Ophthalmol Vis Sci 55, 2284-2289, doi:10.1167/iovs.13-13369 (2014). 


\section{University Library}

\section{- M M I N E R VA A gateway to Melbourne's research publications}

Minerva Access is the Institutional Repository of The University of Melbourne

Author/s:

Tu, MY;Yazar, S;Mackey, DA;Lee, SSY

Title:

How many young drivers do not meet the driver licencing vision requirements?

Date:

2020-05-13

Citation:

Tu, M. Y., Yazar, S., Mackey, D. A. \& Lee, S. S. Y. (2020). How many young drivers do not meet the driver licencing vision requirements? CLINICAL AND EXPERIMENTAL OPHTHALMOLOGY, 48 (6), pp.853-854. https://doi.org/10.1111/ceo.13772.

Persistent Link:

http://hdl.handle.net/11343/275746 